\title{
CONTROL DE CALIDAD DE UNA MARCA DE TISANAS DE BOLDO COMERCIALIZADA EN COSTA RICA DE ACUERDO CON LOS LINEAMIENTOS DEL REGLAMENTO TÉCNICO CENTROAMERICANO
}

\author{
Carvajal Vásquez, Carolina ${ }^{1}$; Castro Villalobos, Pamela ${ }^{1}$ y Mora Román, Juan José \\ 1Estudiantes de Licenciatura en Farmacia de la Universidad de Costa Rica, San José, Costa Rica. ${ }^{2}$ Departamento de \\ Farmacia Industrial, Facultad de Farmacia, Universidad de Costa Rica, San José, Costa Rica.
}

\section{Resumen:}

Justificación y objetivo: el Laboratorio de Análisis y Asesoría Farmacéutica (LAYAFA) de la Universidad de Costa Rica ha venido trabajando en el control de calidad de las tisanas como parte de la vigilancia estatal de productos naturales por parte del Ministerio de Salud. Se buscó evaluar aspectos referentes a la calidad de las tisanas de boldo de una marca comercializada en Costa Rica, mediante pruebas establecidas por el RTCA (Reglamento Técnico Centroamericano).

Métodos: Se realizaron las siguientes pruebas estipuladas en el RTCA: pruebas organolépticas, determinación de materias extrañas, requisitos de etiquetado, prueba de cenizas, llenado mínimo, recuento total de microorganismos aerobios, recuento total de hongos filamentosos y levaduras, determinación específica de E. coli y Salmonella sp.

Resultados: Las pruebas organolépticas discreparon con lo establecido en la literatura oficial, debido a la presencia de materias extrañas. Sin embargo, estuvo conforme al separar dichas materias. No se hallaron seis de los rubros establecidos para los requisitos de etiquetado. Se obtuvo un 11\% para la prueba de cenizas totales, y para la prueba de llenado mínimo, un promedio de 92\%, con dos tisanas con valores menores al $90 \%$. Las pruebas de recuento total de microorganismos aerobios, y de hongos filamentosos y levaduras fueron 400 y 6000 UFC (unidades formadoras de colonia)/g de producto, respectivamente, mientras que hubo ausencia de E. coli y Salmonella sp.

Conclusión: El producto se encuentra conforme de acuerdo a los valores establecidos para los ensayos, con excepción de los requisitos de etiquetado y de llenado mínimo.

Palabras clave: medicina herbal, boldo, control de calidad (NLH, MeSH).

Recibido: 12 Octubre 2014. Aceptado: 18 Enero 2015. Publicado: 15 Abril 2015.

Revista electrónica publicada por el Departamento de Farmacología de la Escuela de Medicina de la Universidad de Costa Rica, 2060 San José, Costa Rica. ${ }^{\circledR}$ All rights reserved. Licensed under a Creative Commons Unported License. 


\title{
QUALITY CONTROL OF A TRADEMARK OF BOLDO TISANES COMMERCIALIZED IN COSTA RICA ACCORDING TO CENTRAL AMERICA TECHNICAL REGULATION GUIDELINES
}

\begin{abstract}
:
Aim: The Laboratory of Pharmaceutical Analysis and Assessment (LAYAFA in Spanish) of the Universidad de Costa Rica has been working in the quality control of the tisanes as part of the Health Ministry state vigilance of natural products. The objective was to evaluate characteristics in regard to the quality of a trademark of boldo tisanes commercialized in Costa Rica, according to the assays established by the Central America Technical Regulation (RTCA in Spanish).

Methods: The following assays stipulated in the RTCA were performed: organoleptic properties, foreign matter determination, labeled requirements, total ash determination, minimum fill, total aerobic microbial count, total combined molds and yeasts count, test for E. coli and Salmonella sp.

Results: The organoleptic properties differ, in some way, from the parameters established in the official literature, because of the presence of foreign matter. Though, it was according to the assay when this matter was separated. For the labeled requirements, six entries were not found. The total ash determination brought a mean value of $11 \%$ and for the minimum fill, its mean value was $92 \%$, with two tisanes with values lower than 90\%. The total aerobic microbial count and total combined molds and yeasts count assays were respectively 400 and $6000 \mathrm{CFU}$ (colony forming units)/g of product, while there was absence of E. coli and Salmonella sp.

Conclusion: The product is according to the values established for the assays, with exception of labeled requirements and minimum fill.
\end{abstract}

Keywords: herbal medicine, boldo, quality control (NLH, MeSH).

\section{INTRODUCCIÓN}

Según la Organización Mundial de la Salud (OMS), se estima que el $80 \%$ de la población mundial utiliza distintas presentaciones de medicinas herbales, como es el caso de las tisanas, para algunos aspectos del cuidado de su salud primaria [1]. Esto ha cobrado un gran auge, debido al alto costo que tienen los medicamentos sintéticos, los cuales no están al alcance de toda la población

Lo anterior ha llevado al desarrollo de procesos de industrialización para estas presentaciones. Uno de los aspectos primordiales de los mismos es la calidad de la materia prima, pues se relaciona con la eficacia y la seguridad del producto final. Mientras que a la materia prima sintética la define su estructura química, la de origen natural exhibe una composición variable. Esto es problemático porque su calidad depende de factores externos como las condiciones edáficas y climáticas, las condiciones de almacenamiento, la época de recolección, las técnicas de cultivo, el ataque de insectos, y de factores internos como el órgano de

Revista electrónica publicada por el Departamento de Farmacología de la Escuela de Medicina de la Universidad de Costa Rica, 2060 San José, Costa Rica. ${ }^{\circledR}$ All rights reserved. Licensed under a Creative Commons Unported License. 
la planta utilizado, la edad de la planta y su estado vegetativo [2].

Como consecuencia de estos factores, los compuestos presentes en los productos naturales pueden variar cualitativa y cuantitativamente, siendo importante controlar las diferencias entre los lotes fabricados a partir de drogas vegetales [2].

Lamentablemente, desde 1994 el Congreso de los Estados Unidos redujo el control de la FDA (Food and Drug Administration, por sus siglas en inglés) sobre los suplementos medicinales, haciéndolos más accesibles y menos regulados en el mercado mundial. Sumado a ello, se sabe que entre las principales causas de toxicidad con bebidas herbales se tiene la adulteración y la contaminación del producto. Todo lo mencionado con anterioridad demuestra lo transcendental para el control de calidad en estos productos [1].

Por esto último, el LAYAFA de la Universidad de Costa Rica ha venido trabajando en el control de calidad de las tisanas como parte de la vigilancia estatal de productos naturales por parte del Ministerio de Salud. Para determinarlo, se ha verificado el cumplimiento de la normativa establecida por el RTCA de Productos Naturales. Este reglamento rige a nivel nacional, en cuanto a la verificación de la calidad de productos naturales medicinales comercializados en el país. De este modo, se muestra la importancia de la presente investigación para los consumidores de esta forma farmacéutica en Costa Rica.

Una de las materias primas utilizadas para la elaboración de productos naturales, específicamente tisanas de té, es la hoja de boldo, la cual se muestra en la figura 1. Su nombre científico es Peumus boldus. Es una especie perteneciente a la familia Monimiaceae. Otros nombres que recibe son boldo folium, boldus, boldus boldus, boldine y boldu, entre otros [3]. Es originario de las zonas montañosas de Perú y Chile. Crece también de forma abundante en las costas del Mediterráneo, las montañas de los Andes y las costas norteamericanas [4].

En la actualidad, la hoja de boldo administrada de forma oral es empleada para espasmos gastrointestinales leves y como estimulante biliar [4]. Junto con esto, se ha investigado la capacidad de la boldina, su principal alcaloide, para actuar como antioxidante, a través de la prevención o retardo de los procesos oxidativos en los lípidos, proteínas y ácidos nucleicos por acción de los radicales libres [5]. Estos efectos han sido determinados mediante diversas investigaciones, las cuales son citadas en una valoración realizada por parte del Comité de Productos Herbales de la EMA (European Medicines Agency, por sus siglas en inglés) para las hojas de esta planta en 2009 [6].

Su selección para el control de calidad fue por tratarse de una droga que es importada, sin darse los controles adecuados para asegurar su seguridad, calidad y eficacia. Por lo tanto, la presente investigación evaluó algunos aspectos referentes a la calidad de las tisanas de Peumus boldus de una marca comercial distribuida en Costa Rica, mediante pruebas establecidas por parte del RTCA.

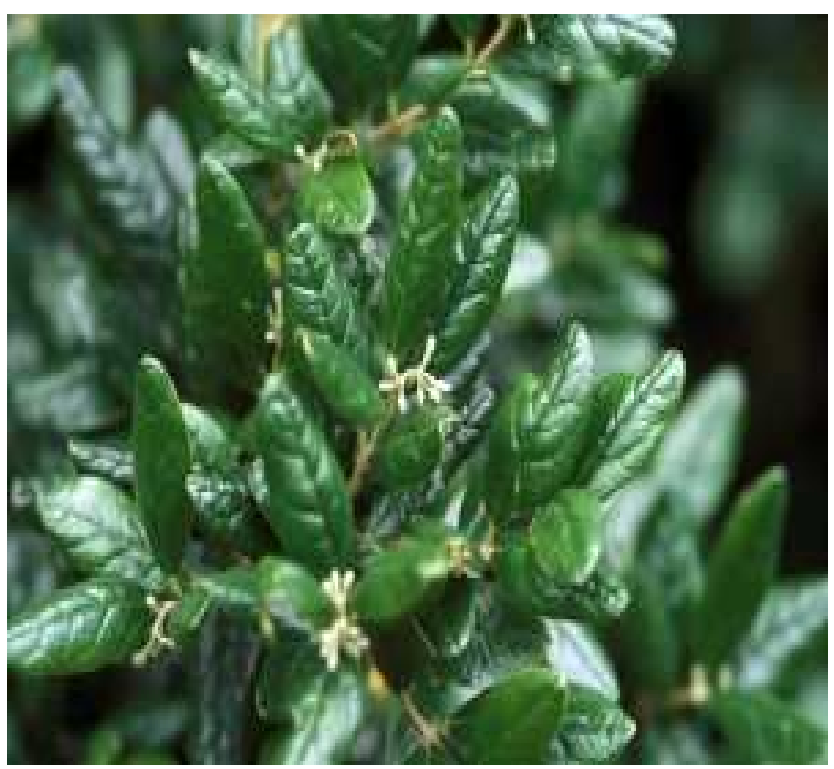

Figura 1: Planta de boldo [7].

Revista electrónica publicada por el Departamento de Farmacología de la Escuela de Medicina de la Universidad de Costa Rica, 2060 San José, Costa Rica. ${ }^{\circledR}$ All rights reserved. Licensed under a Creative Commons Unported License. 


\section{MÉTODOS Y MATERIALES}

Uno de los aspectos importantes referentes a los ensayos para esta investigación consistió en su búsqueda a partir de distintas referencias. Esto se debe a que el RTCA indica como requisito que el procedimiento se halle en alguno de los libros oficiales a nivel nacional.

\section{PRUEBAS ORGANOLÉPTICAS}

Se determinaron las características establecidas en la Farmacopea Británica 2009 con respecto al color, olor y textura de la hoja de boldo [8]. Para ello, se emplearon diez tisanas y las inspecciones se realizaron de forma directa, haciendo uso de un estereoscopio Premiere ${ }^{\circledR}$ SMZ-07 y una lámpara de escritorio para mejorar la iluminación. El producto se encontraba conforme si presentaba un color marrón o marrón verdoso, un olor característico al frotarlo y una textura granulosa.

\section{DETERMINACIÓN DE MATERIAS EXTRAÑAS}

Se tomaron diez tisanas, se esparció su contenido a modo de capa fina sobre una superficie blanca limpia y se inspeccionó cuidadosamente con ayuda de una lupa luminosa Konus $^{\circledR}$ y unas pinzas. Seguidamente, se clasificó la materia extraña en órganos foráneos y en elementos extraños, según lo establece la Farmacopea Británica [8]. Finalmente, se pesó cada materia por separado en una balanza analítica Adam $^{\circledR}$ PW254 y se determinó el porcentaje presente con respecto a la totalidad de la muestra. El producto se encontraba conforme si el porcentaje de órganos foráneos era menor o igual al $4 \%$ y el de elementos extraños era menor o igual al $2 \%$ respecto a la totalidad de la muestra.

\section{REQUISITOS DE ETIQUETADO}

Se evaluaron las condiciones generales de etiquetado exigidas por el RTCA [9], el cual establece como obligatorio la presencia de 19 rubros informativos en el empaque secundario de todo producto natural. Dichos rubros se indican en la tabla III de la sección de resultados.

\section{PRUEBA DE CENIZAS}

El procedimiento se realizó de acuerdo con lo establecido por la Organización Mundial de la Salud para el control de calidad de plantas medicinales [10]. Para ello, se colocaron 2 gramos de material seco, distribuidos en muestras de alrededor de un gramo, pesado con exactitud en una balanza analítica Adam ${ }^{\circledR}$ PW254 y colocado en un crisol, el cual fue llevado a peso constante empleando una estufa Thermo Scientific ${ }^{\circledR}$ Thermolyne y a una temperatura de $450{ }^{\circ} \mathrm{C}$ (no se alcanzó los $500{ }^{\circ} \mathrm{C}$ establecidos por el ensayo) durante 40 minutos para luego permitir su enfriamiento por 30 minutos hasta llevar a peso constante los crisoles con las muestras. La exposición de las muestras se realizó bajo las mismas condiciones descritas para llevar el crisol a peso constante. A partir de esto, se obtuvo el promedio de los porcentajes obtenidos en los diferentes crisoles. El producto se encontraba conforme si el porcentaje promedio de cenizas totales era menor o igual al $13 \%$ del peso inicial de la muestra.

\section{LLENADO MÍNIMO}

A partir de lo indicado en el capítulo general $<755>$ de la Farmacopea de los Estados Unidos [11], se tomaron diez tisanas del té de boldo. A continuación, se extrajo cuantitativamente el contenido de cada tisana, cortándola de tal forma que quedara abierta y con el cuidado de no perder contenido alguno presente en la misma. Seguidamente, se pesó el contenido de cada una en la balanza analítica Adam ${ }^{\circledR}$ PW254. Se calculó un promedio de los valores obtenidos. El producto se encontraba conforme si el contenido neto promedio de las 10 tisanas no era menor que la cantidad declarada y el contenido neto de cualquier tisana no era menos del $90 \%$. Si no se cumplía estas especificaciones, se debía determinar el contenido de 20 tisanas adicionales y el contenido promedio de las 30 tisanas no debía ser menor que la cantidad declarada y el contenido neto de no más de 1 de las 30 tisanas era menos del $90 \%$ de la cantidad declarada. 


\section{RECUENTO TOTAL DE MICROORGANISMOS AEROBIOS}

En este ensayo, se empleó el método de placas del capítulo <61> de la Farmacopea de los Estados Unidos [11]. Se tomó una muestra de un gramo, obtenido a partir de distintas tisanas. Este se suspendió en caldo de soya tripticasa Bacto $^{\circledR}$ número de catálogo 211825 para obtener $10 \mathrm{~mL}$ (dilución 10-1). A continuación, se tomó $1 \mathrm{~mL}$ de esta muestra y se vertió en $9 \mathrm{~mL}$ de caldo soya tripticasa Bacto ${ }^{\circledR}$ (dilución $10^{-2}$ ). Este último paso se repitió para tener una dilución $10^{-3}$. A continuación, se tomaron seis placas de Petri, dos para cada una de las diluciones y a cada una se le colocó un mililitro de la respectiva dilución. A continuación, se agregaron $20 \mathrm{~mL}$ de agar soya tripticasa Bacto ${ }^{\circledR}$ número de catálogo 236950, el cual se hallaba a alrededor de $50{ }^{\circ} \mathrm{C}$, a cada placa, se rotaron suavemente para esparcir uniformemente la muestra en el medio y se esperó a la solidificación de su contenido a temperatura ambiente. Las placas se invirtieron y se incubaron a $33,5{ }^{\circ} \mathrm{C}$ durante 48 horas. Se realizó un conteo de las UFC en las placas con las diluciones donde fuera adecuado el conteo y se obtuvo un promedio de ambas. El producto se encontraba conforme si el conteo era menor a $10^{7} \mathrm{UFC} /$ gramo de producto [12].

\section{RECUENTO TOTAL DE HONGOS FILAMENTOSOS Y LEVADURAS}

En este ensayo, se empleó el método de placas del capítulo <61> de la Farmacopea de los Estados Unidos [11]. Se realizó el mismo procedimiento descrito en recuento total de microorganismos aerobios para la obtención de las diluciones requeridas y la preparación de las placas de Petri. Seguidamente, se agregaron $20 \mathrm{~mL}$ de agar papa dextrosa Difco ${ }^{\circledR}$ número de catálogo 213400 , el cual se encontraba a alrededor de $50{ }^{\circ} \mathrm{C}$, a cada placa, se rotaron suavemente y se esperó a la solidificación de su contenido a temperatura ambiente. Las placas se invirtieron y se incubaron a $22,5{ }^{\circ} \mathrm{C}$ durante 5 días. Finalmente, se realizó el mismo conteo indicado para el recuento total de microorganismos aerobios. El producto se encontraba conforme si el conteo era menor a $10^{5}$ UFC/gramo de producto [12].

\section{DETERMINACIÓN ESPECÍFICA DE E. COLI}

En este ensayo, se empleó el método de placas del capítulo <61> de la Farmacopea de los Estados Unidos [11]. Se tomó una muestra de un gramo, obtenido a partir de distintas tisanas. Este se suspendió en caldo de soya tripticasa Bacto ${ }^{\circledR}$ para obtener $10 \mathrm{~mL}$. La muestra se incubó a $33,5{ }^{\circ} \mathrm{C}$ durante 24 horas. Después de este período, el envase con la muestra se agitó y se transfirió $1 \mathrm{~mL}$ de la misma a $100 \mathrm{~mL}$ de Caldo MacConkey Difco ${ }^{\circledR}$ número de catálogo 220100, se mezcló y se incubó a $44{ }^{\circ} \mathrm{C}$ durante 24 horas. Seguidamente, se subcultivó por duplicado $1 \mathrm{~mL}$ en placas de Agar MacConkey BBL ${ }^{\circledR}$ número de catálogo 211387 a $33,5{ }^{\circ} \mathrm{C}$ durante 24 horas. El producto se encontraba conforme en caso de ausencia de este patógeno [12].

\section{DETERMINACIÓN SALMONELLA SP.}

ESPECÍFICA DE

En este ensayo, se empleó el método de placas del capítulo <61> de la Farmacopea de los Estados Unidos [11]. Se empleó el mismo procedimiento indicado en determinación específica de $E$. coli para la preparación e incubación de la muestra. Después de este período, el envase con la muestra se agitó y se transfirió $0,1 \mathrm{~mL}$ de la misma a $10 \mathrm{~mL}$ de Caldo Rappaport-Vassiliadis R10 Difco ${ }^{\circledR}$ número de catálogo 218581, se mezcló y se incubó a 33,5 ${ }^{\circ} \mathrm{C}$ durante 24 horas. Como siguiente paso, se subcultivó por duplicado $1 \mathrm{~mL}$ en placas de Agar Xilosa Lisina Desoxicolato Difco ${ }^{\circledR}$ número de catálogo 278850 a $33,5{ }^{\circ} \mathrm{C}$ durante 24 horas. El producto se encontraba conforme en caso de ausencia de este patógeno [12].

\section{RESULTADOS}

Para la caracterización organoléptica del boldo presente dentro de la tisana, se realizó una 
cuidadosa observación visual. Los resultados de este ensayo se aprecian en la tabla I.

Junto con la caracterización organoléptica, se procedió a determinar la presencia de órganos foráneos y elementos extraños. De acuerdo a la tabla II, no hubo presencia de elementos extraños, pero sí de órganos foráneos, especialmente ramas y trozos de tallo.

En cuanto a la revisión del empaque secundario, donde se encontraban las tisanas, se buscaron los 19 aspectos mencionados por el RTCA. Con base en la tabla III, es relevante señalar que aspectos fundamentales referentes a una droga de cualquier origen como lo son las condiciones de almacenamiento, las interacciones, los efectos adversos, la posología y la vía de administración no se mostraban en el mismo.

Para el ensayo de cenizas totales, se logró obtener un promedio de $11 \%$ de cenizas totales. La información completa del mismo se exhibe en la tabla IV.
En cuanto a la prueba de llenado mínimo, el producto presentó un valor promedio menor al etiquetado señalado en el empaque secundario del producto y dos de las tisanas presentaron un valor menor al 90\% de dicho etiquetado. En la tabla V, se muestran todos los valores obtenidos mediante este ensayo.

Finalmente, para los ensayos biológicos, se halló la presencia de $400 \mathrm{UFC} / \mathrm{g}$ de producto para el conteo de organismos aerobios totales (se emplearon las placas con la dilución $10^{-2}$, pues las placas con la dilución $10^{-1}$ tenían muchas colonias, lo que dificultaba su lectura, mientras que en aquellas con la dilución $10^{-3}$ no se apreció la presencia de colonias), en tanto que para el conteo de hongos y levaduras, el valor fue $6000 \mathrm{UFC} / \mathrm{g}$ (tanto las placas con la dilución $10^{-2}$ como las de la dilución $10^{-3}$ dieron valores idénticos, mientras que aquellas con la dilución $10^{-1}$ tenían muchas colonias, lo que dificultaba su lectura). Junto con ello, estos ensayos mostraron la ausencia de los microorganismos patógenos E. coli y Salmonella sp.

Tabla I. Caracterización organoléptica de las tisanas de boldo de una marca comercializada en Costa Rica

\begin{tabular}{|c|c|}
\hline Propiedad Organoléptica & Observaciones \\
\hline Color & Verde amarillento \\
\hline Olor & Agradable, fuerte al frotarlo \\
Textura & Granulosa \\
\hline
\end{tabular}

Tabla II. Materias extrañas presentes en las tisanas de boldo de una marca comercializada en Costa Rica

Tipo de materia extraña

Muestra inicial

Órganos foráneos

Elementos extraños
Cantidad

(g)

10,1818

0,4032

0
Porcentaje

(\%)

100

4

0

Revista electrónica publicada por el Departamento de Farmacología de la Escuela de Medicina de la Universidad de Costa Rica, 2060 San José, Costa Rica. ${ }^{\circledR}$ All rights reserved. Licensed under a Creative Commons Unported License. 
Tabla III. Rubros de etiquetado presentes en las tisanas de boldo de una marca comercializada en Costa Rica

\begin{tabular}{|c|c|c|}
\hline Información & Presente & Observaciones \\
\hline Nombre del producto & Sí & \\
\hline Forma farmacéutica & Sí & \\
\hline Indicaciones & Sí & $\begin{array}{l}\text { Interior del empaque } \\
\text { secundario }\end{array}$ \\
\hline Modo de empleo & Sí & \\
\hline $\begin{array}{l}\text { Composición cuali-cuantitativa de ingredientes activos por forma } \\
\text { dosificada }\end{array}$ & Sí & \\
\hline Número de inscripción & Sí & \\
\hline Nombre del laboratorio fabricante y país de origen & Sí & \\
\hline Cantidad neta del producto terminado & Sí & \\
\hline Número de lote & Sí & \\
\hline Condiciones de almacenamiento & No & \\
\hline Fecha de vencimiento & Sí & \\
\hline Contraindicaciones y advertencias & Sí & $\begin{array}{l}\text { Interior del empaque } \\
\text { secundario }\end{array}$ \\
\hline Interacciones & No & \\
\hline Efectos adversos & No & \\
\hline Leyendas generales & Sí & $\begin{array}{l}\text { Interior del empaque } \\
\text { secundario }\end{array}$ \\
\hline Leyendas especiales & No & \\
\hline Posología & No & \\
\hline Vía de administración & No & \\
\hline $\begin{array}{l}\text { Uso durante embarazo, lactancia, en ancianos y niños menores de } 2 \\
\text { años }\end{array}$ & Sí & $\begin{array}{l}\text { Interior del empaque } \\
\text { secundario }\end{array}$ \\
\hline
\end{tabular}

Tabla IV. Determinación de las cenizas totales en las tisanas de boldo de una marca comercializada en Costa Rica

\begin{tabular}{|c|c|c|c|c|c|}
\hline Muestra & $\begin{array}{c}\text { Masa inicial } \\
\mathbf{( g )}\end{array}$ & Masa 1 (g) & Masa 2 (g) & Masa 3 (g) & $\begin{array}{c}\text { Porcentaje cenizas } \\
\text { totales (\%) }\end{array}$ \\
\hline 1 & 1,0015 & 0,1088 & 0,1070 & 0,1066 & 11 \\
\hline 2 & 1,0026 & 0,1120 & 0,1085 & 0,1084 & 11 \\
\hline Promedio & 1,0020 & 0,1104 & 0,1078 & 0,1075 & 11 \\
\hline
\end{tabular}

Revista electrónica publicada por el Departamento de Farmacología de la Escuela de Medicina de la Universidad de Costa Rica, 2060 San José, Costa Rica. ${ }^{\circledR}$ All rights reserved. Licensed under a Creative Commons Unported License. 
Tabla V. Llenado mínimo de las tisanas de boldo de una marca comercializada en Costa Rica

\begin{tabular}{|c|c|c|}
\hline Muestra & $\begin{array}{c}\text { Masa } \\
\mathbf{( g )}\end{array}$ & $\begin{array}{c}\text { Porcentaje Contenido } \\
\text { Etiquetado (\%) }\end{array}$ \\
\hline 1 & 0,9885 & 89 \\
\hline 2 & 0,9802 & 89 \\
\hline 3 & 1,0014 & 91 \\
\hline 4 & 1,0332 & 94 \\
\hline 5 & 1,0183 & 93 \\
\hline 6 & 1,0228 & 93 \\
\hline 8 & 1,0040 & 91 \\
\hline 9 & 1,0419 & 95 \\
\hline 10 & 1,0133 & 92 \\
\hline Promedio & 1,0821 & 98 \\
\hline Desviación Estándar & 1,0186 & No aplica \\
\hline Etiquetado unitario & 0,0293 & No aplica \\
\hline
\end{tabular}

\section{DISCUSIÓN}

Al analizar el contenido de 10 tisanas de hoja de boldo (tabla I), se obtuvo características distintas en cuanto a color respecto a las establecidas en el material de referencia, ya que presentaba un color verde amarillento con trazas de materiales de color más oscuras. Al no presentar un patrón uniforme de color, el resultado discrepaba en cierta medida con lo establecido por la British Pharmacopeia [8], aunque si resultaba similar. Dicho cambio en el color se debió a la presencia de otras partes de la planta, además de su hoja, como se discutirá posteriormente.

Por otro lado, la muestra presentó un olor característico y agradable, el cual fue más evidente al frotar el material seco, tal como lo especificaba dicha farmacopea. Esto demostró como la hoja de boldo conservaba sus propiedades aromáticas (constituida por aproximadamente un $2 \%$ de aceites esenciales), a pesar de las pérdidas en sus componentes aromáticos volátiles por los procesos de secado, molienda y almacenaje. Entre los principales compuestos responsables de su aromaticidad se encuentran el limoneno, el pineno y el $p$-cimeno, el ascaridol, el alcanfor, el cineol, y el linalol [13].

En lo referente a la determinación de materias extrañas, se contabilizó la cantidad de órganos foráneos, los cuales correspondieron a la materia vegetal constituyente de la planta, pero que no forman parte de la materia prima, en este caso, la hoja de boldo. Como se indica en la tabla II, se obtuvo un 4\% para órganos foráneos, cumpliendo así con las especificaciones establecidas en la Farmacopea Británica, donde se dicta el valor encontrado como porcentaje límite admitido respecto al total de la muestra para preparaciones compuestas por hoja de boldo seca [8].

Otro parámetro estudiado fue la presencia de elementos extraños, con lo cual se buscó materia que no provenía de la planta, ni de materia vegetal 
o mineral. Para esta prueba, no se encontró elemento alguno o impureza que no correspondiera a alguna parte de la planta. Por ello, se encontraba dentro de los límites establecidos por la farmacopea [8]. Además, se comprobó la ausencia de insectos y otras contaminaciones animales, tal como lo estipula el material de referencia empleado. Esto constata Buenas Prácticas de Manufactura para el producto estudiado, dentro de las cuales se incluyen condiciones de almacenamiento, procesamiento, técnicas de cultivo y recolección, para cumplir con los requisitos básicos de calidad, seguridad y eficacia del producto.

Por otra parte, para los requisitos de etiquetado, de los 19 rubros exigidos, seis no fueron encontrados en el empaque secundario del producto (tabla III). Los rubros ausentes son de preocupación, debido a que la falta de los mismos puede poner en peligro a las personas que emplean esta sustancia para cualquiera de los usos mencionados con anterioridad. Por ejemplo, la ausencia de indicaciones sobre condiciones de almacenamiento se considera alarmante, pues si bien es trascendental la preservación de la calidad en los procesos de manufactura, el consumidor debe conocer la manera correcta para su manipulación y su conservación. De esta manera, evitará la contaminación del mismo, con las alteraciones en su salud derivadas de su consumo.

Otro detalle es la ausencia de posología. Esto podría resultar peligrosa, pues se reporta en la literatura que a dosis muy altas y prolongadas, el boldo podría ser hepatotóxico, debido a su contenido de alcaloides, principalmente el ascaridol. Por tal razón, debe emplearse con precaución. La dosis recomendada son dos a cinco gramos en forma de infusión para adultos, y no es recomendado en períodos de lactancia o gestación [4].

Para finalizar con el análisis, no se mencionan datos sobre interacciones del boldo, y se han reportado algunas de cuidado, como el consumo en conjunto con antiplaquetarios, que puede tener

Revista electrónica publicada por el Departamento de Farmacología de la Escuela de Medicina de la Universidad de Costa Rica, 2060 San José, Costa Rica. ${ }^{\circledR}$ All rights reserved. Licensed under a Creative Commons Unported License. efectos aditivos con estos fármacos e incrementar el riesgo de sangrado. En cuanto a las contraindicaciones, su ingesta en combinación con otras drogas hepatotóxicas sería de gran peligro, al incrementarse el riesgo de daño hepático [4].

Por todo esto, es necesario incluir dicha información en el empaque y así, contribuir al buen uso de esta planta medicinal en el país.

Siguiendo con el control de calidad requerido, en la prueba de cenizas totales, las muestras cumplieron con el porcentaje establecido como máximo en la Farmacopea de la OMS (tabla IV) [10], con lo cual la materia prima utilizada para las tisanas no se encontraba contaminada con materia inorgánica como metales pesados y partículas minerales, reafirmando la prueba de elementos extraños, donde se determinó de manera visual la ausencia de algún material que no fuese proveniente de la planta como tal.

Con respecto a la prueba de llenado mínimo, tal y como se observa en el cuadro $\mathrm{V}$, el contenido neto promedio de diez tisanas de té de boldo presentó un valor menor al etiquetado $(1,100$ gramos por tisana), y junto con esto, dos de ellas contenían menos del $90 \%$ del contenido etiquetado. Por esta razón, este producto no se encontraba conforme con los criterios de la prueba. Sin embargo, a pesar de ello, no se afecta la calidad del producto desde el punto de vista del RTCA, dado que el reglamento únicamente exige esta prueba en caso de vigilancia sanitaria o denuncia recibida [12].

Finalmente, de acuerdo con las especificaciones para la determinación de recuento microbiano, las tisanas de boldo comercializadas en Costa Rica sí cumplen con lo establecido por este reglamento a partir de la información presentada en la sección de resultados. Sin embargo, un detalle relevante es que estos valores obtenidos podrían disminuir mediante el mejoramiento del proceso de manipulación, tanto de la materia prima como durante la fabricación del producto. 
Un punto adicional en este reglamento es que los productos naturales medicinales para uso humano a los que se les agrega agua a temperatura ambiente antes de su uso, no deben presentar los microorganismos patógenos Salmonella sp. y E. coli [12]. De igual forma, se establece que debe haber ausencia de la segunda en los productos a los que se les agrega agua hirviendo antes de su uso, como lo son las tisanas. En el producto analizado, se comprobó la ausencia de ambos patógenos. Esta ausencia también garantiza el cumplimiento de las Buenas Prácticas de Cultivo y Manufactura, como el control del agua para la irrigación de la planta utilizada.

Vale la pena resaltar que las especificaciones seguidas en estos ensayos microbianos fueron para el producto al cual se le agrega agua hirviendo (excepto para la prueba de ausencia de Salmonella sp.). A pesar de que la forma farmacéutica tisana se debe colocar en agua hirviendo por un tiempo determinado, o bien hervir la planta (hierba aromática) o partes de ella colocadas en agua [14], ésta no es una práctica común. Usualmente, los consumidores calientan el agua, pero sin llevarla hasta ebullición y no esperan un tiempo adecuado para promover el contacto del producto con el agua. Estas prácticas pueden aumentar el riesgo que en esta infusión haya presencia de microorganismos resistentes a altas temperaturas, afectando su salud. Junto con ello, no se garantiza el efecto terapéutico deseado, al no haber una extracción completa del principio activo del material de la tisana.

\section{CONCLUSIONES}

Las tisanas de boldo de la marca comercializada en Costa Rica cumplen con las pruebas de control de calidad como la caracterización organoléptica (excepto por las diferencias observadas debido a la presencia de otras partes de la planta), la determinación de materias extrañas y la prueba de cenizas. Sin embargo, se debe prestar atención con su llenado mínimo, pues esta prueba se encontró no conforme.
Por otra parte, de acuerdo con las especificaciones de etiquetado establecidas por el RTCA, su empaque secundario no posee la información suficiente establecida por este documento y su ausencia puede poner en peligro a las personas que emplean esta sustancia para cualquiera de sus usos terapéuticos.

Finalmente, el producto analizado sí cumple con los límites de conteo de aerobios totales, así como de hongos y levaduras, y hay ausencia de E. coli y Salmonella sp.

Como siguiente aproximación, será necesario realizar estos ensayos con al menos tres lotes diferentes del producto y llevar a cabo las pruebas restantes no ejecutadas en esta oportunidad (determinación de metales pesados, determinación de arsénico, pérdida por secado, determinación por secado, identificación general o específica y cenizas insolubles en ácido).

\section{BIBLIOGRAFÍA}

1. Hartmann AM, Raap DK, Geist CR. Toxicity of herbal beverages. En: Preedy VR, Watson RR, editores. Reviews in Food and Nutrition Toxicity. Vol 1. Londres: Taylor \& Francis; 2003. p. 1-15.

2. Mangiaterra PA. Evaluación de parámetros botánicos y fitoquímicos para el control de calidad de «carqueja» [Tesis]. Buenos Aires: Facultad de Ciencias Exactas y Naturales, Universidad de Belgrano; 2004.

3. Therapeutic Research Faculty. Boldo. http://naturaldatabase.therapeuticresearch.com/nd /Search.aspx?cs=\&s=ND\&pt=100\&id=593\&ds=\&na me=BOLDO\&searchid $=48543340.2013$. Accesado 6 de abril de 2013.

4. European Scientific Cooperative on Phytotherapy. The Scientific Foundation for Herbal Medicinal Products. 2 ed.. Exeter: Thieme; 2003.

5. Villar del Fresno AM, Gómez-Serranillos P. Boldo: Indicaciones terapéuticas. Revista Farmacia Profesional. 2006; 20 (4): 74-78.

Revista electrónica publicada por el Departamento de Farmacología de la Escuela de Medicina de la Universidad de Costa Rica, 2060 San José, Costa Rica. ${ }^{\circledR}$ All rights reserved. Licensed under a Creative Commons Unported License. 
6. Comité de productos medicinales herbales. Assessment Report on Peumus boldus Molina, Folium. Agencia Europea de Medicamentos. Londres; 2009.

7. Comisión Nacional de Investigación Científica y Tecnológica. Molécula derivada del boldo: Una nueva alternativa de tratamiento para la distrofia muscular. http://www.

Conicyt.cl/fondef/2014/08/28/molecula-derivadadel-boldo-una-nueva-al ternativa-de-tratamientopara-la-dist rofia-muscular/. 2014. Accesado el 14 de enero de 2015.

8. British Pharmacopoeia Commission. British Pharmacopoeia. British Pharmacopoeia Commission. The Stationery Office on behalf of the Medicines and Healthcare products Regulatory Agency: Londres; 2008.

9. Consejo de Ministros de Integración Económica Centroamericana. RTCA 11.04.41:06. Consejo de Ministros de Integración Económica Centroamericana.

10. Organización Mundial de la Salud. Quality Control Methods for medicinal plants materials. WHO Library Cataloguing in Publication Data: Ginebra; 1998.

11. The United States Pharmacopoeial Convention. United States Pharmacopoeia 35 and National Formulary 30. The United States Pharmacopoeial Convention: Maryland; 2012.

12. Consejo de Ministros de Integración Económica Centroamericana. RTCA 11.03.56:09. Reglamento Técnico Centroamericano. Productos Farmacéuticos, Productos Naturales Medicinales para Uso Humano. Verificación de la calidad. San José; 2011.

13. Awang DVC. Tyler's Herbs of Choice: The Therapeutic Use of Phytomedicinals. 3ed.. Florida: Taylor \& Francis; 2009.

14. Rojas C, Tripaldi P, Dután H. Desarrollo y optimización de una infusión aromática tipo tisana aplicando el diseño de Plackett Burman y optimización de máxima pendiente. Revista de Ciencias. 2010; 14(1): 103-123.

\section{INFORMACIÓN DEL AUTOR}

Mora Román, Juan José

Email: juanjose.moraroman@ucr.ac.cr 